\title{
Effects of Fulvic Concentration and Molecular Size on Complexation of Am and Pu with Aquatic Fulvic Acids
}

\author{
S. Nagao, ${ }^{*, a}$ Y. Sakamoto, ${ }^{\text {b }}$ T. Tanaka, ${ }^{\text {b }}$ Y. Nakaguchi, ${ }^{c}$ and R. R. Rao ${ }^{d}$ \\ ${ }^{a}$ Faculty of Environmental Earth Science, Hokkaido University, Sapporo 060-0810, Japan \\ ${ }^{\mathrm{b}}$ Tokai Research and Development Center, Japan Atomic Energy Agency, Tokai, Ibaraki 319-1195, Japan \\ ${ }^{\mathrm{c}}$ School of Science and Technology, Kinki University, Higashi-Osaka, Osaka 577-8502, Japan \\ ${ }^{\mathrm{d}}$ Chalk River Laboratories, Atomic Energy of Canada Limited, Chalk River, Ontario KOJ1J0, Canada
}

Received: December 19, 2006; In Final Form: July 13, 2007

\begin{abstract}
The association properties of $\mathrm{Am}$ and $\mathrm{Pu}$ with aquatic fulvic acid in a $0.01 \mathrm{M} \mathrm{NaClO}_{4}$ solution at $\mathrm{pH}$ 6-7 were studied on the basis of molecular size distribution. Seven fulvic acids (FA) were isolated from river, lake, and groundwater samples using XAD extraction technique. They were used for comparison of their effects on the association of $\mathrm{Am}$ and $\mathrm{Pu}$. In the absence of $\mathrm{FA}$, about $80 \%$ of $\mathrm{Am}$ and $75 \%$ of $\mathrm{Pu}$ were found to have molecular size greater than $450 \mathrm{~nm}$ (particulate forms). On the other hand, in the presence of FA, particulate forms of Am and $\mathrm{Pu}$ decreased with increasing FA concentration, and were negligible at the FA concentration of $10 \mathrm{mg} / \mathrm{L}$. Both $\mathrm{Am}$ and $\mathrm{Pu}$ were associated mainly with aquatic FA having two size fractions of $30-10 \mathrm{kDa}$ or less than $5 \mathrm{kDa}$. The differences between $\mathrm{Am}$ and $\mathrm{Pu}$ were rather small and the association patterns were divisible into two groups: size-selective and non-size-selective. Complexation of FA with Am and Pu was controlled by the amount of FA, the percentage, and characteristics of each size fraction of FA.
\end{abstract}

\section{Introduction}

The environmental behavior of actinides is dependent on whether the actinides are injected in the environments as source-dependent or source-independent species. ${ }^{1}$ The mobility of actinides is also controlled by complex physico-chemical interactions that depend largely on the properties and characteristics of actinides, the aquifer, and the suspended solids. Association with colloidal organic materials such as humic substances (humic and fulvic acids) is a well-recognized decisive factor for the fate of actinides in surface aquatic environments. $^{2-4}$

Most organic materials in natural waters are humic substances that are polydispersed mixtures of natural organic polyelectrolytes and brown or black complex organic acids of widely various molecular weights. ${ }^{5}$ These substances are heterogeneous mixtures of many molecules which vary from region to region. For that reason, they cannot be treated as simple complex forming ligands. ${ }^{2,6-8}$ Studies of the chemical characterization of humic and fulvic acids indicate that the amounts of different functional groups vary considerably among humic substances of different origin. ${ }^{9-11}$ The association of actinides-lanthanides with humic substances was found in different molecular size fractions through field observations ${ }^{12-15}$ and laboratory experiments. ${ }^{16-19}$ These molecular size effects of humic substances on the complexation affinity and sorption ability might considerably affect the migration behavior of actinides. ${ }^{17,18,20}$

This study reports association properties of $\mathrm{Am}$ and $\mathrm{Pu}$ with aquatic fulvic acid, the dominant fraction of humic substances in natural waters, based on their molecular size distribution. The aquatic fulvic acids were isolated from two shallow groundwater samples and other samples obtained from three rivers and a lake surface. Those substances were then examined to compare their effects on the association of $\mathrm{Am}$ and $\mathrm{Pu}$.

*Corresponding author. E-mail: nagao@ees.hokudai.ac.jp. Fax: +81-11-706-2349.

\section{Experimental}

2.1. Environmental conditions of aquatic fulvic acids. Fulvic acids (FA) were isolated from three river water samples (Yodo, Yamato, and Suwannee Rivers) and a Norwegian surface water sample, each of different environmental conditions. The Yodo River is a major river running through the Kinki region, which is a very heavily populated urban area in Japan. The river water originates from Lake Biwa in Shiga Prefecture, and is supplied from the lake at $40 \mathrm{~m}^{3} / \mathrm{s}^{21}$ The Yamato River is located in the Osaka Plain and Nara Basin in the Kinki region and has a watershed area of $1070 \mathrm{~km}^{2}$. It originates from the Kasachi mountain area, and runs through a heavily populated urban area. The Suwannee River rises in the Okefenokee Swamp and flows through southern Georgia and northern Florida. Most of the Okefenokee Swamp drains into the Suwannee River. ${ }^{22,23}$ The Nordic samples were obtained from a reservoir of Vallsjorden, Norway. The reservoir is at $225 \mathrm{~m}$ above sea level and has a maximum depth of about 14 $m$. The Suwannee and Nordic waters are brownish. Groundwater humic substances from the Glass Block site (GB) and Wallace Point (WP) in the Chalk River Laboratories of Atomic Energy of Canada Limited were also used in this study. The GB site is located in the recharge area for a shallow sand aquifer. That recharge area is a seasonal wetland and the subsurface residence time for the groundwater is of approximately one year. Wallace Point is located in the discharge zone of an overburden flow system. Physicochemical properties of water samples are shown in Table $1 .^{21-23}$

2.2. Isolation and preparation of fulvic acids. The Yodo and Yamato FA were isolated from a 140-L river water sample collected at a downstream site of the Yodo and Yamato Rivers. From the GB and the WP sites, 20,000 L and 10,000 L, respectively, of shallow groundwater were collected. The isolation and purification of humic substances were carried out using the column method with XAD- 8 or DAX- 8 resin. ${ }^{25}$ The amounts of humic substances were $0.04 \mathrm{~g}$ for the Yodo, $0.08 \mathrm{~g}$ for the Yamato, $18.2 \mathrm{~g}$ for the GB, and $9.3 \mathrm{~g}$ for the WP. Suwannee River and Nordic FA isolated by the XAD-8 extrac- 
TABLE 1: Characteristics of water samples

\begin{tabular}{|c|c|c|c|}
\hline Sample & $\mathrm{pH}$ & Conductivity $/ \mathrm{mS} \mathrm{m}^{-1}$ & $\mathrm{DOC} / \mathrm{mg} \mathrm{L}^{-1}$ \\
\hline Yodo River, Japan ${ }^{a}$ & 7.4 & 17 & 2.1 \\
\hline Yamato River, Japan $^{b}$ & 7.7 & & 5.3 \\
\hline Suwannee River, U.S.A. ${ }^{c}$ & 3.9 & 41 & 37.7 \\
\hline Nordic, Norwegian surface water ${ }^{d}$ & 5.6 & 21 & 10.7 \\
\hline Groundwater Glass Block site, Canada ${ }^{b}$ & 5.7 & & 2.3 \\
\hline Groundwater Wallace Point, Canada $^{b}$ & 7.1 & & 1.7 \\
\hline
\end{tabular}

${ }^{a}$ Water Quality Management Center for Osaka Pref. ${ }^{21}{ }^{b}$ This work. ${ }^{c}$ Miles et al. ${ }^{22}{ }^{d}$ IHSS. $^{23}$

TABLE 2: Elemental composition and functional groups of fulvic acids

\begin{tabular}{|c|c|c|c|c|c|c|}
\hline \multirow[t]{2}{*}{ Sample } & \multicolumn{4}{|c|}{ Elemental composition / \% } & \multicolumn{2}{|c|}{ Functional groups $/ \mathrm{meq}^{-1}$} \\
\hline & $\mathrm{C}$ & $\mathrm{H}$ & $\mathrm{N}$ & $\mathrm{O}$ & Carboxyl & Phenolic \\
\hline Suwannee $\mathrm{FA}^{a, b}$ & 53.0 & 4.4 & 0.8 & 43.9 & 6.5 & 1.6 \\
\hline Nordic FA ${ }^{a, b}$ & 52.3 & 4.0 & 0.7 & 45.1 & 6.4 & 1.6 \\
\hline Glass Block site HS ${ }^{c}$ & 53.2 & 5.6 & 0.8 & 40.3 & 7.8 & 0.86 \\
\hline Wallace Point HS ${ }^{c}$ & 52.8 & 5.4 & 0.8 & 41.0 & 9.9 & 1.9 \\
\hline
\end{tabular}

The unit of elemental composition is expressed on an ash-free basis. The Yodo FA was not determined for the above parameters because of small sample amounts. The contents of functional groups were measured using potentiometric titration or ${ }^{13} \mathrm{C}-\mathrm{NMR}$ spectroscopy. ${ }^{a}$ IHSS. ${ }^{23}{ }^{b}$ Calculated from data of Ritchie and Perdue. ${ }^{25}{ }^{c}$ This work.

tion procedure were purchased from the International Humic Substances Society (IHSS). The elemental composition of the FA is given in Table $2 .{ }^{23,26}$ The chemical composition of GB and WP humic substances indicates fulvic-like characteristics and is consistent with the occupation of FA in natural waters. ${ }^{5}$

A stock solution of the FA was prepared by dissolving $10 \mathrm{mg}$ of the purified FA in a dilute $\mathrm{NaOH}$ solution. Then the solution was made up to $100 \mathrm{~mL}$ of $0.01 \mathrm{M} \mathrm{NaClO}_{4}$. The solution was adjusted to $\mathrm{pH} 8$ by adding dilute $\mathrm{HClO}_{4}$. All fulvic stock solutions were stored in a refrigerator at $4{ }^{\circ} \mathrm{C}$.

2.3. Complexation experiments. Association experiments were carried out in a medium of $0.01 \mathrm{M} \mathrm{NaClO}_{4}$ solution at the fulvic concentration of $1-20 \mathrm{mg} / \mathrm{L}$ and $\mathrm{pH}$ 6-7. A nitrate solution of ${ }^{238} \mathrm{Pu}$ and ${ }^{241} \mathrm{Am}$ was used for experiments. A stock solution containing ${ }^{238} \mathrm{Pu}$ was prepared through dilution with deionized water. The stock solution was adjusted to $\mathrm{pH} 4$ using $\mathrm{NaOH}$ solution. Valence of ${ }^{238} \mathrm{Pu}$ in the stock solution was confirmed as $\mathrm{Pu}(\mathrm{IV})$ using TTA-xylene extraction method. A stock solution containing ${ }^{241} \mathrm{Am}$ was also prepared using a similar procedure. In addition, $100 \mu \mathrm{L}$ of ${ }^{238} \mathrm{Pu}$ and ${ }^{241} \mathrm{Am}$ solution was added to $10 \mathrm{~mL}$ of fulvic solution in a Teflon centrifugation tube. The initial concentrations of $\mathrm{Am}$ and $\mathrm{Pu}$ was respectively (1.0-7.6) $\times 10^{-8} \mathrm{M}$ and $(3.0-7.6) \times 10^{-6} \mathrm{M}$. After 7 days of shaking in an oven at $25^{\circ} \mathrm{C}$, the solution was filtered with $450 \mathrm{~nm}$ filters and measured for $\mathrm{pH}$.

Ultrafiltration technique was used to size-fractionate Am and $\mathrm{Pu}$ in the fulvic solutions because it is a non-destructive and reagent-free method. The sample solution was sequentially ultrafiltered with simple ultrafiltration filters (Ultrafree CL filters; Millipore Corp.) having nominal cut-off molecular weights of $100 \mathrm{kDa}, 30 \mathrm{kDa}$ (polyethersulfone membrane filters), $10 \mathrm{kDa}$, and $5 \mathrm{kDa}$ (regenerated cellulose membrane filters). The radioactivity of ${ }^{238} \mathrm{Pu}$ and ${ }^{241} \mathrm{Am}$ was measured for each molecular size fraction using liquid scintillation counting. The percentage of Am and $\mathrm{Pu}$ in each molecular size range was calculated from the radioactive concentration in each molecular size fraction. The molecular size distribution of the fulvic acid was measured using ultrafiltration technique or high-performance size exclusion chromatography according to a method described elsewhere. ${ }^{27}$

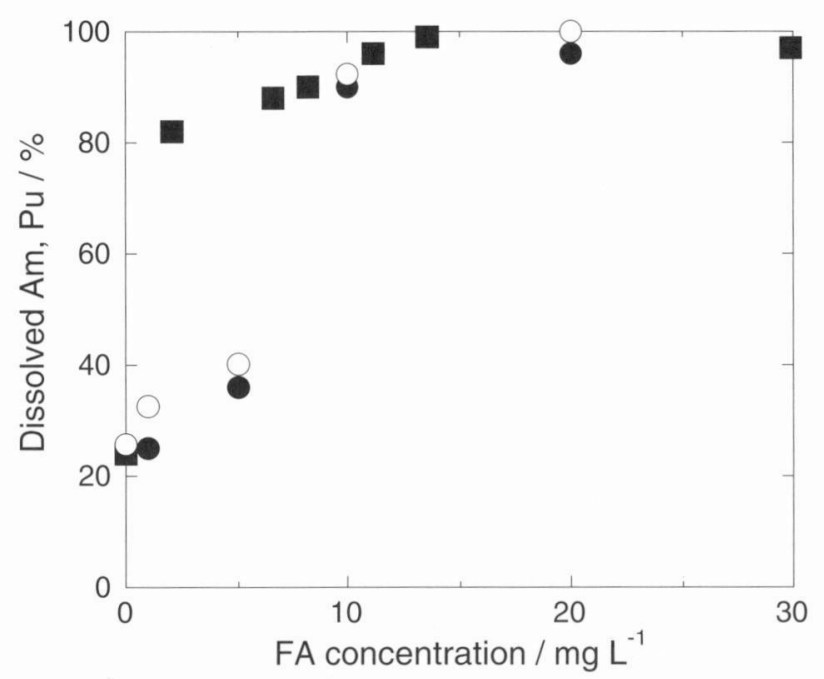

Figure 1. Dissolved fraction of $\mathrm{Am}$ and $\mathrm{Pu}$ in the absence and presence of the Yodo and Yamato River fulvic acid (FA) as a function of FA concentration: Am-Yodo FA system at pH 5.8-6.2; $\mathbf{A m}$ Yamato FA system at $\mathrm{pH}$ 6.8-7.1; O Pu-Yodo FA system at $\mathrm{pH} 6.0-$ 6.7 .

\section{Results and Discussion}

3.1. Effects of fulvic concentration on complexation with Am and Pu. Figure 1 shows the percentage of dissolved Am and $\mathrm{Pu}$ as a function of FA concentration. The dissolved Am rapidly increases at the FA concentration of $5 \mathrm{mg} / \mathrm{L}$. Based on kinetic estimation, in the absence of FA, 77\% of Am and 74\% of $\mathrm{Pu}$ were found in the molecular size greater than $450 \mathrm{~nm}$ (particulate forms) at $\mathrm{pH} \mathrm{6-7}$ as a result of polymerization and/ or precipitation. The percentage of dissolved $\mathrm{Am}$ and $\mathrm{Pu}$ increases with increasing FA concentration, indicating the complexation of $\mathrm{Am}$ and $\mathrm{Pu}$ with the Yodo FA. Particulate forms of $\mathrm{Am}$ and $\mathrm{Pu}$ are negligible at the FA concentration of $10 \mathrm{mg} / \mathrm{L}$.

The molecular size distribution of dissolved Am and Pu in the absence and presence of the Yodo and Yamato FA is shown in Figure 2. Size fractions of increased Am are less than $5 \mathrm{kDa}$ 

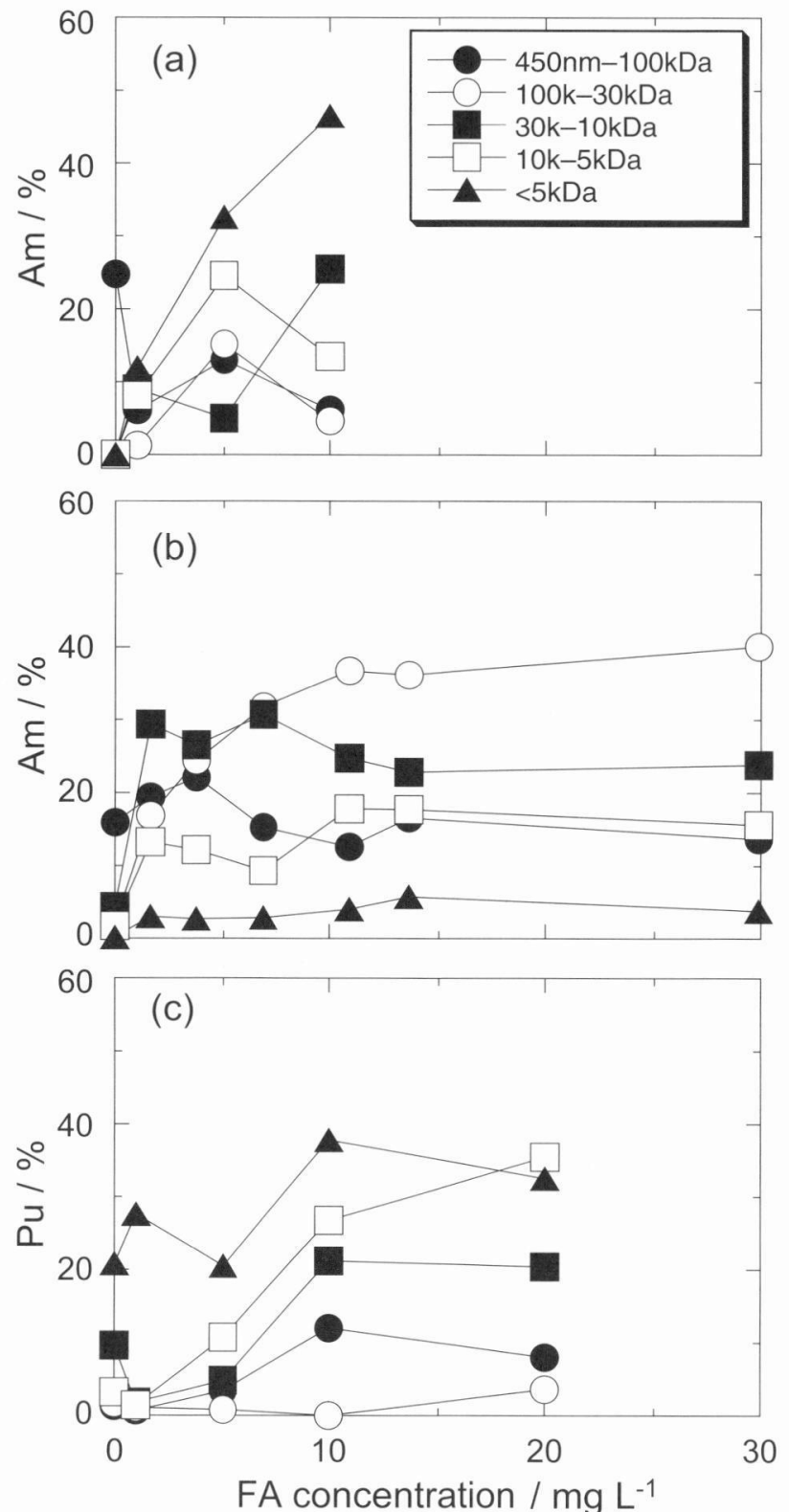

Figure 2. Molecular size distribution of $\mathrm{Am}$ and $\mathrm{Pu}$ in the presence of aquatic fulvic acids (FA) as a function of FA concentration: (a) Am-Yodo FA system; (b) Am-Yamato FA system; (c) Pu-Yodo FA system.

at Am-Yodo FA and 100-10 kDa at the Am-Yamato FA system. In the presence of $\mathrm{FA}$, the percentage of $\mathrm{Pu}$ in the size fraction of 30-5 kDa increases with the FA concentration. On the other hand, the variation in $\mathrm{Pu}$ is not great for the size fraction less than $5 \mathrm{kDa}$; it is nearly equal to that at the blank experiment. However, we cannot identify whether Pu-fulvic complexes and/ or $\mathrm{Pu}$ ionic species are present. Apparently, $\mathrm{Pu}$ is complexed with FA having specific molecular size fractions.

3.2. Dissolved forms of $\mathrm{Am}$ and $\mathrm{Pu}$ in the presence of fulvic acid with different origin. The molecular size distribution of $\mathrm{Am}$ and $\mathrm{Pu}$ in the presence of FA with different origin is shown in Figure 3. In the presence of Suwannee and Nordic FA, which are isolated from brownish water with high DOC concentration (Table 1), the dominant size fraction of Am is $30-10 \mathrm{kDa}(64-74 \%)$. On the other hand, the major part of Am in the presence of FA isolated from uncolored natural waters is found for molecular size less than $5 \mathrm{kDa}$ at the AmYodo FA, Am-GB HS, and Am-WP HS systems. The dominant size fractions of $\mathrm{Pu}$ are less than $5 \mathrm{kDa}$ for the Yodo FA, $\mathrm{GB}$, and WP humic substances (38-43\%) and 30-10 kDa for the Suwannee and Nordic FA (57-64\%).

The molecular size distribution of FA is shown in Figure

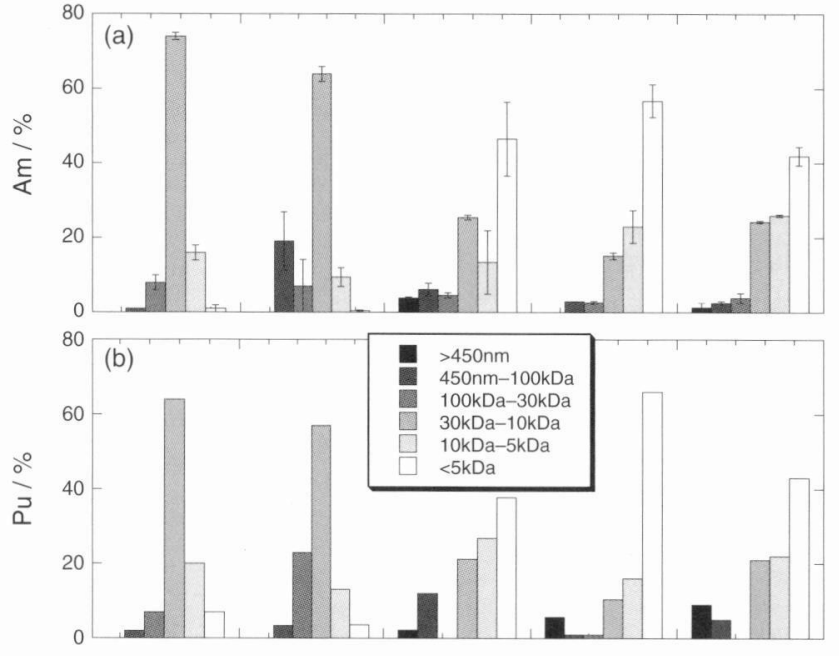

$8 0 \longdiv { \text { (c) } }$

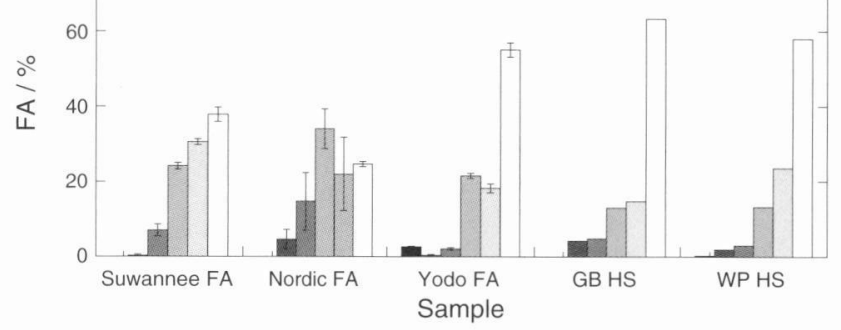

Figure 3. Molecular size distribution of (a) Am and (b) $\mathrm{Pu}$ in the presence of aquatic fulvic acids and (c) fulvic acids themselves in a $0.01 \mathrm{M} \mathrm{NaClO}_{4}$ solution. The $\mathrm{pH}$ of sample solutions was $\mathrm{pH}$ 5.8-6.5 for Am-FA, pH 5.8-7.0 for $\mathrm{Pu}-\mathrm{FA}$, and $\mathrm{pH}$ 5.0-6.0 ( $\mathrm{pH} 8$ for the Suwannee) for the FA. The error bars indicate deviation from mean value $(n=2)$.

3(c). The dominant size of the FA is $30-10 \mathrm{kDa}$ for the Nordic sample, and less than $5 \mathrm{kDa}$ for the Suwannee and the Yodo FA and the groundwater humic substances. A similar size distribution was observed among $\mathrm{Am}$ and $\mathrm{Pu}$ in the presence of FA, and FA itself. A discrepancy in the molecular size distribution exists between Am and Pu in the presence of Suwannee-Nordic FA and the fulvic acids themselves.

3.3. Complexation properties related to molecular size distribution of fulvic acid. Figure 4 shows that a positive correlation exists between the percentage of Am and FA in each size fraction (correlation factor, $r=0.93$ ) except for the size fractions of $30-10 \mathrm{kDa}$ and less than $5 \mathrm{kDa}$ at the AmSuwannee and Am-Nordic FA experimental systems. A similar positive correlation exists $(r=0.93)$ between $\mathrm{Pu}$ and FA, except for the Suwannee and Nordic with $30-10 \mathrm{kDa}$ and $<5$ $\mathrm{kDa}$. Table 3 summarizes the percentages of $\mathrm{Am}$ and $\mathrm{Pu}$ in the dominant size fractions. We assumed that $\mathrm{Pu}$ in the size fraction less than $5 \mathrm{kDa}$ was present as fulvic complexes on the basis of the size distribution of $\mathrm{Pu}$ in soil solutions. ${ }^{28}$ The respective mean ratios of $\mathrm{Am}-\mathrm{FA} / \mathrm{FA}$ and $\mathrm{Pu}-\mathrm{FA} / \mathrm{FA}$ are $0.82 \pm$ 0.09 and $0.82 \pm 0.19$ for the size fraction of $<5 \mathrm{kDa}$. On the other hand, the size fraction of $30-10 \mathrm{kDa}$ for the Suwannee and Nordic FA has different complexation affinities for Am and $\mathrm{Pu}$. The averaged $\mathrm{Am}-\mathrm{FA} / \mathrm{FA}$ and $\mathrm{Pu}-\mathrm{FA} / \mathrm{FA}$ ratios are, respectively, $2.5 \pm 0.6$ and $2.2 \pm 0.5$.

Size selective complexation of fulvic-like materials with Am and $\mathrm{Pu}$ has been reported for laboratory experiments and field studies. ${ }^{15,19,29}$ Matsunaga et al. ${ }^{15}$ showed that a size fraction of $100-10 \mathrm{kDa}$ was dominant for ${ }^{239,240} \mathrm{Pu}(67 \%)$ and ${ }^{241} \mathrm{Am}(59 \%)$ in surface water in the Chernobyl nuclear accident area. The ratios of $\mathrm{Am} / \mathrm{DOC}$ and $\mathrm{Pu} / \mathrm{DOC}$ of the size-fractionation are 2.5-2.8 and are similar to our experimental data of the fraction of 30-10 kDa (Table 3). The different characteristics among 
TABLE 3: Dominant molecular size (MS) of Am and Pu in the presence of fulvic acid (FA)

\begin{tabular}{|c|c|c|c|c|c|}
\hline Sample & Dominant MS & Am-FA / \% & $\mathrm{Pu}-\mathrm{FA} / \%$ & Am-FA/FA ratio & $\mathrm{Pu}-\mathrm{FA} / \mathrm{FA}$ ratio \\
\hline Suwannee FA & $30-10 \mathrm{kDa}$ & 74 & 64 & 3.1 & 2.6 \\
\hline Nordic FA & $30-10 \mathrm{kDa}$ & 64 & 57 & 1.9 & 1.7 \\
\hline Yodo FA & $<5 \mathrm{kDa}$ & 47 & 38 & 0.84 & 0.69 \\
\hline Glass Block site HS & $<5 \mathrm{kDa}$ & 57 & 66 & 0.90 & 1.0 \\
\hline Wallace Point HS & $<5 \mathrm{kDa}$ & 42 & 43 & 0.72 & 0.74 \\
\hline
\end{tabular}

Am-FA (or Pu-FA) means Am (Pu) in the presence of FA.
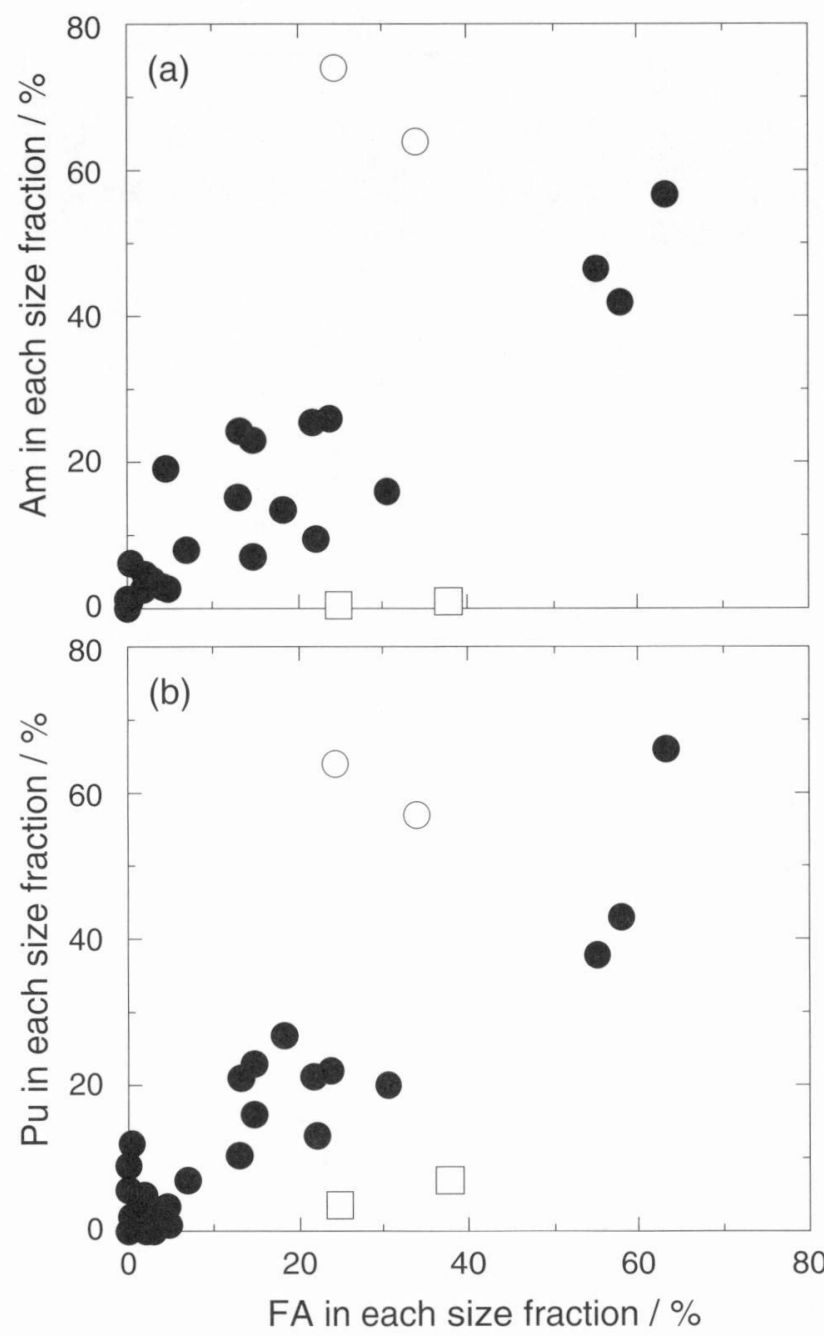

Figure 4. Relationships in percentage between (a) Am and (b) Pu in the presence of fulvic acids and fulvic acids in respective size fractions. The symbols indicate molecular size fractions: $\bigcirc 30-10 \mathrm{kDa}$ and $\square<5 \mathrm{kDa}$ at the Suwannee-Nordic FA systems; $\bullet$ other size fractions at the Suwannee-Nordic FA systems and other systems.

size-fractionated humic and fulvic acids are presented. ${ }^{12,30-32}$

Consistent results for $\mathrm{Am}$ and $\mathrm{Pu}$ were obtained using 2-step and/or 4-step size fractionation for river, lake, and soil solutions. ${ }^{15,28}$ Figure 4 shows that the slope $(0.77)$ of the regression line at the Am-FA experimental system was in agreement with that $(0.80)$ of the Pu-FA system. These results indicate that size-dependent complexation occurs in Am and Pu with FA in a $0.01 \mathrm{M} \mathrm{NaClO}_{4}$ solution at $\mathrm{pH} \mathrm{6-7}$ and fulvic concentration of $10 \mathrm{mg} / \mathrm{L}$.

Consequently, the association properties for Am-FA and $\mathrm{Pu}-$ FA complexes depend on molecular size distribution and characteristics in each size of surface water humic substances that are supplied from the watershed of river systems and groundwater humic substances in different recharge areas and geo- logic media. Fulvic acids in uncolored natural waters exhibit size-dependent complexation with $\mathrm{Am}$ and $\mathrm{Pu}$. On the other hand, FA in colored natural waters show three complexation properties as follows: 1) the size-dependent complexation at $450 \mathrm{~nm}-30 \mathrm{kDa}$ and $10-5 \mathrm{kDa} ; 2$ ) the size selective complexation at $300-10 \mathrm{kDa} ; 3$ ) no complexation for the molecular size less than $5 \mathrm{kDa}$. The molecular size of $30-10 \mathrm{kDa}$ for the FA has different characteristics such as functional groups in comparison with that of FA in uncolored waters. These results suggest that molecular size distribution and each size fraction of FA are one of factors controlling the complexation.

Acknowledgements. This study was conducted partly within the framework of the Cooperative Research Project between the Japan Atomic Energy Research Institute (present: Japan Atomic Energy Agency) and the Atomic Energy of Canada Limited. This work was supported partially by a Grant-in-Aid (No. 18310002) for Scientific Research from the Ministry of Education, Culture, Sports, Science and Technology of Japan, and a research grant from the Radioactive Waste Management Funding and Research Center.

\section{References}

(1) D. E. Nelson, R. P. Larsen, and W. R. Penrose, Proc. Symp. USDOE, Washington, D. C. (1987), p 27.

(2) G. R. Choppin, Radiochim. Acta 58/59, 113 (1992).

(3) V. Moulin and G. Ouzounian, Appl. Geochem. Suppl. 1, 179 (1992).

(4) V. Moulin, and C. Moulin, Appl. Geochem. 10, 573 (1995).

(5) E. M. Thurman, Organic Geochemistry of Natural Waters, Martinus Nijhoff/Dr. W. Junk Publishers, Dordrecht (1985).

(6) Modelling in Aquatic Chemistry, Eds. I. Grenthe and I. Puigdomenech, OECD Publications, Paris (1997).

(7)E. Tipping, Cation Binding by Humic Substances, Cambridge University Press, Cambridge (2002).

(8) J. Du, N. Sato, and O. Tochiyama, J. Nucl. Radiochem. Sci. 6, 25 (2005).

(9) E. Tombacz, Soil Sci. 164, 814 (1999).

(10) N. Fujitake and M. Kawahigashi, Soil Sci. Plant Nutr. 45, 359 (1999).

(11) I. Christl and R. Kretzschmar, Environ. Sci. Technol. 35, 2505 (2001)

(12) J. S. Gaffney, N. A. Marley, and K. A. Orlandini, Humic and Fulvic Acids: Isolation, Structure, and Environmental Role, Eds. J. S. Gaffney, N. A. Marley, and S. B. Clark, American Chemical Society, Washington D. C. (1996), p 26.

(13) E. L. Cooper, M. K. Hass, and J. F. Mattie, Appl. Radiat. Isot. 46, 1159 (1995).

(14) J. F. McCarthy, K. R. Czerwinski, W. E. Sanford, P. M. Jardine, and J. D. Marsh, J. Contam. Hydrol. 30, 49 (1998).

(15) T. Matsunaga, S. Nagao, T. Ueno, S. Takeda, H. Amano, and Y. Tkachenko, Appl. Geochem. 19, 1582 (2004). 
(16) T. Tanaka, S. Nagao, Y. Sakamoto, T. Ohnuki, S. Ni, and M. Senoo, J. Nucl. Sci. Technol. 34, 829 (1997).

(17) S. Nagao, R. R. Rao, R. W. D. Killey, and J. L. Young, Radiochim. Acta 82, 205 (1998).

(18) T. Tanaka, S. Nagao, Y. Sakamoto, and H. Ogawa, J. Nucl. Sci. Technol. Suppl. 2, 524 (2002).

(19) S. Nagao, N. Fujitake, H. Kodama, T. Matsunaga, and H. Yamazawa, J. Radioanal. Nucl. Chem. 255, 459 (2003).

(20) J. J. Albert, M. A. Wahlgren, D. M. Nelson, and P. J. Jehn, Environ. Sci. Technol. 11, 673 (1992).

(21)Investigation Report for Water Quality of Yodo River System, Water Quality Management Center of Osaka Prefecture, Osaka (1998).

(22) M. S. Mills, E. M. Thurman, J. Ertel, and K. A. Thorn, Humic and Fulvic Acids: Isolation, Structure, and Environmental Role, Eds. J. S. Gaffney, N. A. Marley, and S. B. Clark, American Chemical Society, Washington D. C. (1996), p 151.

(23) IHSS web site: http://www.ihss.gatech.edu/.

(24) D. E. Jackson and K. J. Inch, NHRI Paper No. 7, Scientific Series No. 104, Inland Waters Directorate, Environ. Canada, Ottawa (1980).
(25)E. M. Thurman and R. L. Malcolm, Environ. Sci. Technol. 15, 463 (1981).

(26) J. D. Ritchie and E. M. Perdue, Geochim. Cosmochim. Acta 67, 85 (2003).

(27) S. Nagao, T. Matsunaga, Y. Suzuki, and K. Hiraki, Chikyukagaku (Geochemistry) 35, 107 (2001) (in Japanese with English abstract).

(28) G. I. Agapkina, F. A. Tikhomirov, A. I. Shcheglov, W. Kracke, and K. Bunzl, J. Environ. Radioactivity 29, 257 (1995).

(29) S. Nagao, Y. Sakamoto, T. Tanaka, and R. R. Rao, J. Radioanal. Nucl. Chem. 273, 135 (2007).

(30) A. Tomikawa and Y. Oba, Soil Sci. Plant Nutr. 37, 211 (1991).

(31) R. S. Swift, R. L. Leonard, R. H. Nerman, and B. K. G. Theng, Sci. Total Environ. 117/118, 53 (1992).

(32) N. A. Marley, J. S. Gaffiney, and K. A. Orlandini, Humic and Fulvic Acids: Isolation, Structure, and Environmental Role, Eds. J. S. Gaffney, N. A. Marley, and S. B. Clark, American Chemical Society, Washington D. C. (1996), p 96. 